\title{
An analytical method for chlorinated paraffins and their determination in soil samples
}

\author{
YUAN Bo, WANG YaWei, FU JianJie, ZHANG QingHua* \& JIANG GuiBin \\ State Key Laboratory of Environmental Chemistry and Ecotoxicology, Research Center for Eco-Environmental Sciences, Chinese Academy of \\ Sciences, Beijing 100085, China
}

Received October 23, 2009; accepted April 1, 2010

\begin{abstract}
Short chain chlorinated paraffins (SCCPs) are possibly persistent organic pollutants (POPs), and are candidate POPs of the Stockholm Convention. In this study, three quantitative methods for analyzing CPs were compared using a gas chromatograph-electron capture detector (GC-ECD), gas chromatograph-electron capture negative ion low resolution mass spectrometry (GC-ECNI-LRMS) and gas chromatograph-electron ionization tandem mass spectrometry (GC-EI-MS ${ }^{2}$ ). A quantitative method for the analysis of total CPs in soil samples was established. The environmental levels of CPs in an e-waste dismantling area in China were evaluated.
\end{abstract}

chlorinated paraffins, short chain chlorinated paraffins, e-waste dismantling areas

Citation: Yuan B, Wang Y W, Fu J J, et al. An analytical method for chlorinated paraffins and their determination in soil samples. Chinese Sci Bull, 2010, 55: 2396-2402, doi: 10.1007/s11434-010-3261-x

As the chlorinated derivatives of $n$-alkanes, chlorinated paraffins (CPs) are widely used in metal-cutting additives and lubricants, plasticizers of paint and sealants, adhesives, and the flame retardant of plastics. CP mixtures are typically divided into three categories corresponding to the length of the carbon chain: $\mathrm{C} 10-\mathrm{C} 13$ (short chain chlorinated paraffins, SCCPs), C14-C17 (medium chain chlorinated paraffins, MCCPs) and C18-C30 (long chain chlorinated paraffins, LCCPs).

CPs have been produced since the 1930s. The usage increased rapidly as an alternative to polychlorinated biphenyls (PCBs) and polychlorinated naphthalenes (PCNs) [1].

Over 10000 homologues, isomers, diastereomers and non-enantiomers of CPs are produced during the chlorination of $n$-alkanes. Therefore, the separation, identification and determination of a single CP compound are not feasible by current quantitative methods. Gas chromatography-mass spectrometry (GC-MS), such as GC-ECNI-LRMS/HRMS, GC-MAB-HRMS, GC-NICI-MS, and GC-EI-MS ${ }^{2}$, is

*Corresponding author (email: qhzhang@ @rcees.ac.cn) widely accepted in the determination of CPs. Other detectors such as ECD and FID have also been employed. Using electron capture negative ion high/low-resolution mass spectrometry, the number of carbon and chlorine atoms in the molecules are determined by monitoring $[\mathrm{M}-\mathrm{Cl}]^{-}$ions of specific $m / z$ value corresponding to formula groups [3-5]. Reth et al. [6] changed the ionization mode of CPs using ECNI with $\mathrm{CH}_{4} / \mathrm{CH}_{2} \mathrm{Cl}_{2}$ as carrier gas and achieved precise quantitative results of chlorinated CP congeners, which also occurs using metastable atom bombardment (MAB) coupled with HRMS [7]. Based on electron ionization tandem mass spectrometry (EI-MS ${ }^{2}$ ), Zencak et al. [8] selected $\mathrm{m} / \mathrm{z} 91$, 102 as common fragment ions for all CPs and determined the total CP amount with CIDs (collision- induced dissociation) by detecting $m / z 91 \rightarrow 53,102 \rightarrow 65$. An ECD detector is usually utilized for analyzing CPs in cutting fluids and sealants [9].

SCCPs are of particular concern because of their high potential for environmental release and relative higher aquatic and mammalian toxicity than other CP products [10]. The presence of SCCPs has been found in various environ- 
mental matrices, including river water, sediment, soil, biota and human milk from different countries and regions, as well as in the atmosphere of remote non-industrial areas and high-latitude polar regions [11-16].

As candidate POPs reviewed by the POP review committee (POPRC) of the Stockholm Convention (SC), the SCCPs proposal has been evaluated against the criteria of Annex D of SC by POPRC in 2007. Comparatively limited work has been carried out regarding the distribution, pollution characteristics, and environmental fate of SCCPs and MCCPs in China, although CPs production and usage are large $[17,18]$.

This work presents different quantitative methods for the determination of SCCPs and MCCPs using GC-ECD, GCECNI-LRMS and GC-EI-MS ${ }^{2}$. A pre-treatment and instrumental method for analyzing the total CPs in soil was established. This method was utilized to preliminarily evaluate the pollution levels of CPs in an e-waste dismantling area.

\section{Materials and methods}

\subsection{Sampling sites and samples collection}

In all, ten soil samples were collected from Taizhou in Zhejiang province in November 2005. Four of the samples were from contaminated areas and the other 6 samples were collected from a control area, about 10-20 km away from the e-waste dismantling area. Each topsoil sample $(0-20 \mathrm{~cm})$ was obtained by mixing at least 5 adjacent sub-samples from one paddy field (4 corners and the center, approximately $10 \mathrm{~m} \times 10 \mathrm{~m}$ ). In addition, one sample from a high altitude area (Wolong, Sichuan Province, China) was also collected as a background area.

\subsection{Materials, standards and reagents}

Cyclohexane, dichloromethane (DCM), n-hexane ( $n \mathrm{Hex})$, toluene and acetone for residue analysis were obtained from Fisher (Hampton, NH). Sulfuric acid, hydrochloric acid and anhydrous sodium sulfate were all guaranteed reagents.

Copper powder $(63 \mu \mathrm{m})$ was washed in hydrochloric acid, and was cleaned by deionized water and acetone before use. Silica gel (0.063-0.100 mm) and Florisil (60-100 mesh) were obtained from Merck (Whitehouse Station, NJ) and activated at $550^{\circ} \mathrm{C}$ for $12 \mathrm{~h}$. Anhydrous sodium sulfate was heated to $600^{\circ} \mathrm{C}$ in a muffle furnace for $6 \mathrm{~h}$.

Reference SCCP (chlorine contents of 51.5\%, 55.5\%, $63.0 \%$ ), MCCP (chlorine contents of $52.0 \%$ and $57.0 \%$ ) and LCCP (C 22, chlorine contents of 72.1\%) with concentrations of $100 \mathrm{ng} \mu \mathrm{L}^{-1}$ in cyclohexane as well as $\varepsilon$-hexachlorocyclohexane ( $\varepsilon-\mathrm{HCH}$, solution in cyclohexane, $10 \mathrm{ng} \mu \mathrm{L}^{-1}$ ) were purchased from Ehrenstorfer GmbH (Augsburg, Germany). ${ }^{13} \mathrm{C}_{10}$-trans-chlordane (100 ng $\mu \mathrm{L}^{-1}$, solution in $n$-nonane, purity $99 \%$ ) were purchased from Cambridge
Isotope Laboratories (Andover, USA). Technical products, CP52 (medium chain, chlorine contents of 52\%) and CP70 (long chain, chlorine contents of $70 \%$ ), were received from factories.

\subsection{Instruments}

GC-ECD measurements were performed using a 6890GC with a DB-5 column (30-m length, 0.25-mm i.d., $0.25 \mu \mathrm{m}$ film thickness). A GC-MS system was employed using a 6890GC-5975N MS with an ECNI source. A 7000A triple quadrupole was combined with a 7890A GC using an electron impact ion source. A sample was injected by a 7683B Series Injector into a DB-5MS (30-m length, 0.25-mm i.d., $0.25 \mu \mathrm{m}$ film thickness) capillary column as well as a GC-ECNI-LRMS system (all of the above instruments and columns were from Agilent Technologies). An accelerated solvent extractor (ASE) was a Dionex ASE 350 (Dionex Canada Ltd., Oakville, ON, Canada), and a rotary evaporator was a Heidolph 4000 .

\subsection{Sample pretreatment}

Soil samples were freeze-dried and homogenized by sieving through a stainless steel 75 -mesh $(0.5 \mathrm{~mm})$ sieve. An aliquot of $5 \mathrm{~g}$ of sample was mixed with $15 \mathrm{~g}$ anhydrous $\mathrm{Na}_{2} \mathrm{SO}_{4}$, spiked with $10 \mathrm{ng}{ }^{13} \mathrm{C}_{10}$-trans-chlordane and extracted by using a Dionex ASE 350 at $100^{\circ} \mathrm{C}$ and 1500 psi. A mixture of dichloromethane and $n$-hexane (1:1) was used as the extraction solvent. The thermal equilibration time was $5 \mathrm{~min}$, and the static extractions were performed within three cycles (10 min/cycle). The cell was purged with gaseous nitrogen for $100 \mathrm{~s}$. After extraction, about $2 \mathrm{~g}$ of activated copper powder was added to the extract to remove elemental sulfur, and filtered through approximately $5 \mathrm{~g}$ of anhydrous sodium sulfate. The extract was rotaryevaporated to about $2 \mathrm{~mL}$ and cleaned by passing through a multi-layered Florisil column containing, from bottom to top, $3 \mathrm{~g}$ of activated Florisil, $2 \mathrm{~g}$ of activated silica gel, $5 \mathrm{~g}$ of acid silica gel $(30 \%, \mathrm{w} / \mathrm{w})$ and $4 \mathrm{~g}$ anhydrous sodium sulfate. The column was pre-cleaned with $50 \mathrm{~mL}$ hexane. After loading the samples, CPs congeners were eluted with $40 \mathrm{~mL}$ hexane followed by $120 \mathrm{~mL}$ DCM and hexane (1:1). The eluent was concentrated to $2 \mathrm{~mL}$ on the rotary evaporator. The volume was further reduced with a gentle nitrogen flow and the solvent was changed to $100 \mu \mathrm{L}$ cyclohexane in a mini vial. $10 \mathrm{ng} \varepsilon-\mathrm{HCH}$ was added and the vial mixed by vortexing prior to GC injection.

\subsection{Instrument analysis}

(1) GC-ECD. The injection temperature was $320^{\circ} \mathrm{C}$, the injection volume $1 \mu \mathrm{L}$ by splitless mode, and the detector temperature was $330^{\circ} \mathrm{C}$. The oven temperature was initially set at $120^{\circ} \mathrm{C}$, held for $4 \mathrm{~min}$, and increased at $15^{\circ} \mathrm{C} \mathrm{min}^{-1}$ to 
$320^{\circ} \mathrm{C}$ and held for $5 \mathrm{~min}$.

(2) GC-ECNI-LRMS. The injector temperature was $250^{\circ} \mathrm{C}$. The oven temperature remained at $100^{\circ} \mathrm{C}$ for $1 \mathrm{~min}$, before being increased at $30^{\circ} \mathrm{C} / \mathrm{min}$ to $310^{\circ} \mathrm{C}$ (held for 22 min). Helium was selected as the carrier gas at a constant flow rate of $36 \mathrm{~cm} / \mathrm{s}$, and the reaction gas was methane. The ion source and transferline temperature were $200^{\circ} \mathrm{C}$ and $275^{\circ} \mathrm{C}$, respectively. The scan range was $60-600(\mathrm{~m} / \mathrm{z}$ ) (scan time: $200 \mathrm{~ms}$ ). Selected ions for the SIM mode were listed in Table 1. Ions for the quantification of MCCPs were as follows [4]: [C14] 335/369/403/437/473/507; [C15] 349/383/ 417/451/487/521; [C16] 363/397/431/465/ 501/535; [C17] 445.

(3) GC-EI-MS ${ }^{2}$. Helium was used as the quench gas at a constant flow rate of $2.25 \mathrm{~mL} / \mathrm{min}$. The initial oven temperature was $100^{\circ} \mathrm{C}(1 \mathrm{~min})$. It was increased to $160^{\circ} \mathrm{C}(5$ min) at $30^{\circ} \mathrm{C} / \mathrm{min}$, increased to $310^{\circ} \mathrm{C}$ at $30^{\circ} \mathrm{C} / \mathrm{min}$ and held for $22 \mathrm{~min}$. Quantifications were carried out with the CIDs $m / z 91 \rightarrow 53$ (collision energies $-10 \mathrm{~V}$ ) and confirmed with $m / z 102 \rightarrow 65(-10 \mathrm{~V})$. The precursor ion $m / z 383$ and the product ion $m / z 276$ were chosen for ${ }^{13} \mathrm{C}_{10}$-trans-chlordane (collision energy $-21 \mathrm{~V}$ ), while for $\varepsilon-\mathrm{HCH}$ they were 219 $\rightarrow 183(-15 \mathrm{~V})$. The conditions for EI-MS ${ }^{2}$ were as follows: electron energy: $70 \mathrm{eV}$, dwell time: $300 \mathrm{~ms}$, resolution of Q1 is wide and of Q3 widest, and nitrogen was used as a collision gas at $1.5 \mathrm{~mL} / \mathrm{min}$. Quantification was carried out using the internal calibration standard method.

(4) Quality assurance and quality control (QA/QC). Strict QA/QC was implemented to ensure the identification and accurate quantification of the target compounds. Sample pretreatment was conducted in a clean room with double
HEPA air filtration and positive ambient pressure. All glassware was thoroughly rinsed with dichloromethane. Method blank samples were included to monitor the contamination. The detector response was linear within the range of 0.25 and $20 \mathrm{ng} \mu \mathrm{L}^{-1}$. A seven-point calibration curve was prepared using individual SCCPs, MCCPs and their mixtures and a linear coefficient value $R^{2}$ was $\geqslant 0.999$. The limit of detection for the sum of CPs was $0.25 \mathrm{ng}$. Mean recoveries of ${ }^{13} \mathrm{C}_{10}$-trans-chlordane was $82.4 \% \pm 17.0 \%$.

\section{Results and discussion}

\subsection{Comparison of ECD, ECNI-LRMS and EI-MS methods for the GC analysis of CPs}

The chromatograms of standards and technical products of CPs using GC-ECD, GC-ECNI-LRMS are shown in Figures 1 and 2.

Figure 1 shows that the similarity of physical and chemical properties among the complex CP congeners caused difficulties for instrumental analysis. The results also implied that $\mathrm{CP}$ congeners cannot be separately from one another using HRGC, which is similar to the results using two-dimensional gas chromatography [19]. GC-ECD cannot supply detailed information about molar compositions and is not suitable for the detection of CPs in environmental matrices. ECD is typically employed in the determination of total CPs in cutting fluids and lubricants $[9,20]$. EI-MS ${ }^{2}$ analyzes total CPs with the advantage of ion selection to reduce inferences although it fails to distinguish CPs with

Table 1 ECNI-MS-Monitored $m / z$ values of [M-Cl] ${ }^{-}$ions and their percentage abundances in the ion formula $\mathrm{C}_{n} \mathrm{H}_{2 n+2-z} \mathrm{Cl}_{z}\left(\mathrm{SCCPs}^{\mathrm{a}}{ }^{2}\right.$

\begin{tabular}{|c|c|c|c|}
\hline \multirow{2}{*}{ Isomer formula $(n, z)$} & \multicolumn{2}{|c|}{$m / z$ (abundance $\%)[3]$} & \multirow{2}{*}{ Retention time window No. } \\
\hline & Quantitation ion & Confirmation ion & \\
\hline 10,6 & $313(35.7 \%)$ & $315(23.2 \%)$ & 1,2 \\
\hline 10,7 & $347(32.3 \%)$ & $349(26.3 \%)$ & $1-3$ \\
\hline 10,8 & $381(28.5 \%)$ & $383(27.8 \%)$ & $2-5$ \\
\hline 10,9 & $417(27.9 \%)$ & $415(24.6 \%)$ & $4-6$ \\
\hline 10,10 & $451(27.1 \%)$ & $449(20.9 \%)$ & $5-7$ \\
\hline 11,7 & $361(32.0 \%)$ & $363(26.0 \%)$ & $2-5$ \\
\hline 11,8 & $395(28.1 \%)$ & $397(27.5 \%)$ & $3-5$ \\
\hline 11,9 & $431(27.6 \%)$ & $429(24.3 \%)$ & 5,6 \\
\hline 11,10 & $465(26.8 \%)$ & $463(20.6 \%)$ & 6,7 \\
\hline 12,6 & $341(34.9 \%)$ & $343(22.8 \%)$ & $2-4$ \\
\hline 12,7 & $375(31.6 \%)$ & $377(25.8 \%)$ & $3-5$ \\
\hline 12,8 & $409(27.8 \%)$ & $411(27.2 \%)$ & $4-6$ \\
\hline 12,10 & $479(26.6 \%)$ & $477(20.4 \%)$ & 6,7 \\
\hline 13,7 & $389(31.3 \%)$ & $391(25.5 \%)$ & $4-6$ \\
\hline 13,8 & $423(27.5 \%)$ & $425(26.9 \%)$ & $4-7$ \\
\hline 13,9 & $459(27.1 \%)$ & $457(23.8 \%)$ & 6,7 \\
\hline
\end{tabular}

a) The peak of highest abundance in the $[\mathrm{M}-\mathrm{Cl}]^{-}$ion group (as a percent of the total of all isotopic combinations) was used for quantification. The next most abundant ion was also monitored for confirmation. Retention time windows (min): 1, 5.00-12.00; 2, 12.00-12.50; 3, 12.5-13.00; 4, 13.00-13.50; 5, $13.50-14.00 ; 6,14.00-14.50 ; 7,14.50-35.00$. 

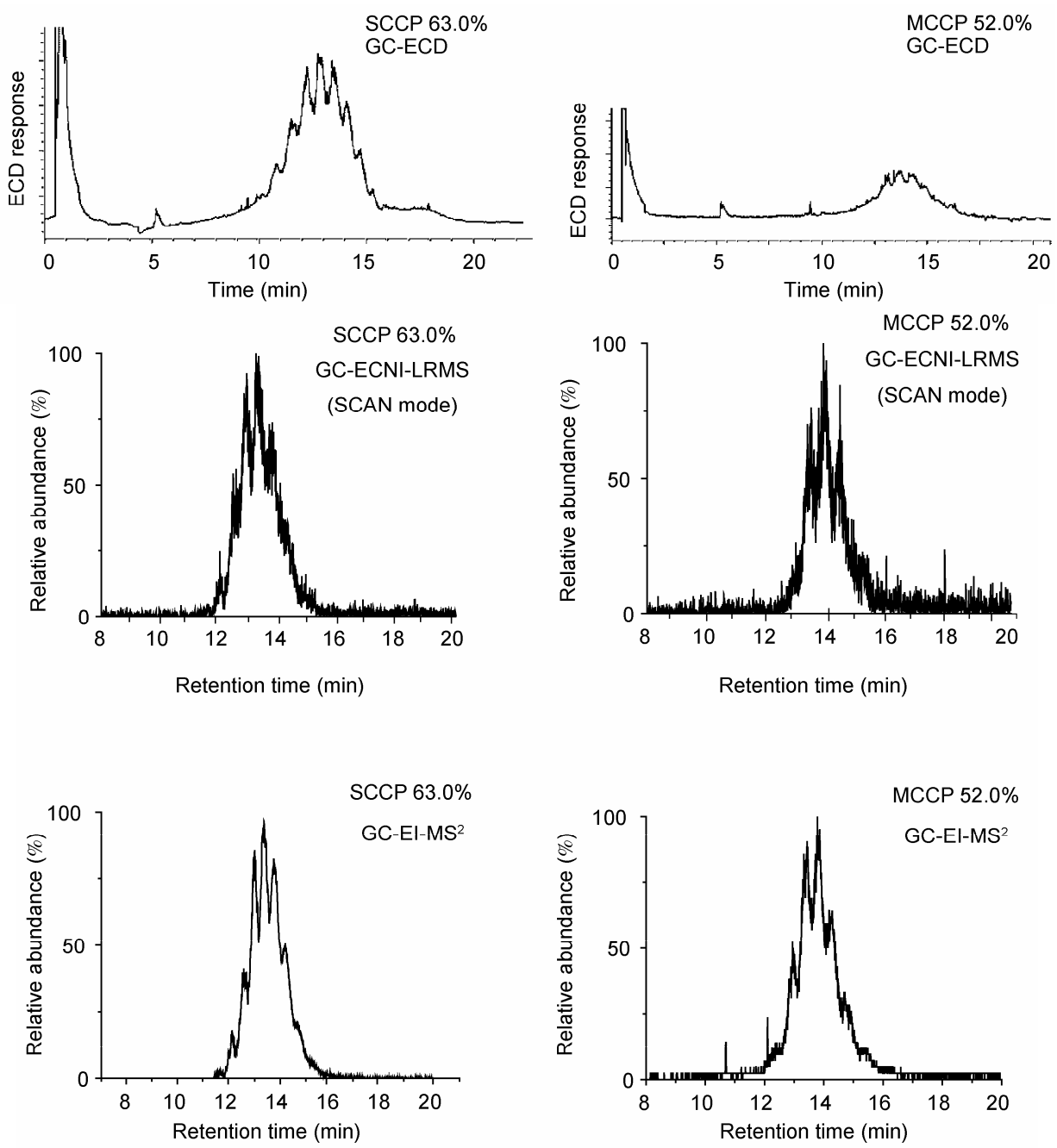

Figure 1 GC-ECD, GC-ECNI-LRMS and GC-EI-MS ${ }^{2}$ Chromatograms of CPs Standards SCCP $63.0 \%$ and MCCP 52.0\%.

different numbers of carbon and chlorine atoms.

Tomy et al. [13] reported the quantification of SCCPs and MCCPs by GC-ECNI-HRMS according to eq.(1):

$$
\frac{\operatorname{Inj}(\mathrm{a})}{\operatorname{Inj}(\mathrm{std})}=\frac{\operatorname{SIM}(\mathrm{a})}{\operatorname{SIM}(\mathrm{std})} \cdot \frac{\mathrm{Ab}(\mathrm{std})}{\mathrm{Ab}(\mathrm{a})} \cdot \frac{M(\mathrm{std})}{M(\mathrm{a})} \text {. }
$$

Inj: moles of injected CPs; SIM: integrated SIM signal; Ab: quantitation ion abundance; $M$ : average molar masses; a: analyte; std: standard.

The concentration and composition of samples are calculated by the ratio of the integrated SIM signal of the internal standard and samples [3]. Using the quantification method mentioned above with ECNI-LRMS, we confirmed the molar composition of the three $\mathrm{CP}$ standards to be: SCCP $51.5 \%$, SCCP $63.0 \%$ and MCCP $52.0 \%$, with the results listed in Table 2. The experimental chlorine contents were higher than the theoretical value, which was consistent with a previous study while the congeners with chlorine numbers $<5$ could not be detected, which was different from the study by Moore et al. [7]. C16 or longer carbon- chain congeners were not found in MCCP $52.0 \%$ (Table 2). The results indicated that errors could occur when using ECNI-MS for detecting lower chlorinated paraffins.

Figure 2 shows the chromatograms of an industrial product (CP52) using GC-ECD, GC-ECNI-LRMS and GC-EI-MS ${ }^{2}$. For industrial production, CP52 (chlorine contents $52 \%, \mathrm{w} / \mathrm{w}$ ) is produced from medium length $n$-paraffins by ultraviolet irradiation. Compared with a standard MCCP mixture $(52.0 \%)$ (Figure 1), more peaks are observed in CP52, which hints that a more complex composition exists in the product. Figure 3(a) and (b) show ECNI-LRMS chromatograms of MCCP $52.0 \%$ and CP52. Compared with the standard, the CP52 product contained C16 and longer chain congeners, which increased the difficulty of congener analysis. Taking $\mathrm{C}_{16} \mathrm{H}_{28} \mathrm{Cl}_{6}$ in $\mathrm{CP} 52$ as an example, compared with $\mathrm{C}_{11} \mathrm{H}_{16} \mathrm{Cl}_{8}$ in SCCP $63.0 \%$ (Figure 3(c)), $\mathrm{m} / z=$ 395 is both the mass-to-charge ratio of $\mathrm{C}_{16} \mathrm{H}_{28} \mathrm{Cl}_{6}$ 's confirmation ion $\left(\mathrm{C}_{16}{ }^{35} \mathrm{Cl}_{4}{ }^{37} \mathrm{Cl}_{1} \cdot\right)$ and $\mathrm{C}_{11} \mathrm{H}_{16} \mathrm{Cl}_{8}$ 's quantification ion $\left(\mathrm{C}_{11}{ }^{35} \mathrm{Cl}_{5}{ }^{37} \mathrm{Cl}_{2} \cdot\right)$, while the retention times of these two ions overlapped each other. Figure $3(\mathrm{~d})(\mathrm{m} / \mathrm{z}=397)$ and 
Table 2 Molar composition of CPs standards, based on the signal ECNI-LRMS ${ }^{\text {a) }}$

\begin{tabular}{|c|c|c|c|}
\hline Isomer formula $(n, z)$ & SCCP 51.5\% molar composition (\%) & SCCP $63.0 \%$ molar composition (\%) & MCCP $52.0 \%$ molar composition (\%) \\
\hline 10,6 & - & 2.1 & - \\
\hline 10,7 & - & 4.2 & - \\
\hline 10,8 & - & 3.0 & - \\
\hline 10,9 & - & 0.9 & - \\
\hline 10,10 & - & 0.4 & - \\
\hline 11,6 & 27.1 & 4.2 & - \\
\hline 11,7 & 6.1 & 15.7 & - \\
\hline 11,8 & - & 13.9 & - \\
\hline 11,9 & - & 4.1 & - \\
\hline 11,10 & - & 0.6 & - \\
\hline 12,6 & 31.5 & 2.4 & - \\
\hline 12,7 & 11.0 & 10.6 & - \\
\hline 12,8 & 0.3 & 14.9 & - \\
\hline 12,9 & - & 6.5 & - \\
\hline 12,10 & - & 0.7 & - \\
\hline 13,6 & 10.7 & - & - \\
\hline 13,7 & 6.9 & 5.2 & - \\
\hline 13,8 & - & 8.9 & - \\
\hline 13,9 & - & 4.9 & - \\
\hline 14,5 & - & - & 0.4 \\
\hline 14,6 & - & - & 33.6 \\
\hline 14,7 & - & - & 48.8 \\
\hline 14,8 & - & - & 8.5 \\
\hline 15,6 & - & - & 7.5 \\
\hline 15,7 & - & - & 5.9 \\
\hline 15,8 & - & - & 0.2 \\
\hline Average molar masses & 366.6 & 443.6 & 448.8 \\
\hline Calculated chlorine contents $(\%, \mathrm{w} / \mathrm{w})$ & 55.9 & 66.2 & 57.9 \\
\hline Theoretical chlorine contents $(\%, \mathrm{w} / \mathrm{w})$ & 51.5 & 63.0 & 52.0 \\
\hline
\end{tabular}

a) The ion formula was $\mathrm{C}_{n} \mathrm{H}_{2 n+2-z} \mathrm{Cl}_{z}$, and the percentage of each congener was adjusted by the chlorine number.

Figure 3(e) $(m / z=399)$ also show the same result. $m / z=$ 397 is the mass-to-charge ratio of $\mathrm{C}_{11} \mathrm{H}_{16} \mathrm{Cl}_{8}$ 's quantification ion $\left(\mathrm{C}_{11}{ }^{35} \mathrm{Cl}_{6}{ }^{37} \mathrm{Cl}_{1} \cdot\right)$, while $\mathrm{m} / z=399$ is $\mathrm{C}_{16} \mathrm{H}_{28} \mathrm{Cl}_{6}$ 's confirmation ion $\left(\mathrm{C}_{16}{ }^{35} \mathrm{Cl}_{3}{ }^{37} \mathrm{Cl}_{2} \cdot\right)$, both of which, however, were detected in the short chain standard and the medium chain product. Therefore, they were not distinguished from each other according to the retention time. Interference existing between the SCCPs and MCCPs mixtures analyzed by LRMS leads to an overestimation of individual congeners and/or total CPs concentrations. $[\mathrm{M}+\mathrm{Cl}]^{-}$is the main fragment ion instead of $[\mathrm{M}-\mathrm{Cl}]^{-}$for low chlorinated compounds, which increases systematic errors during analysis [5].

\subsection{CPs concentrations in soil samples}

Because the interference between SCCPs and MCCPs cannot be effectively eliminated by ECNI-LRMS, EI-MS ${ }^{2}$ was employed for the determination of total CPs in the soil samples. All concentrations reported are on a dry weight (dw) basis.

The chromatograms of the samples from different sections exhibited different polluting characteristics (Figure 4). $\Sigma \mathrm{CPs}$ concentrations of samples from e-waste dismantling areas of the samples ranged from 911 to $4726 \mathrm{ng} / \mathrm{g}$ with an average value of $2689 \mathrm{ng} / \mathrm{g}$, which were higher than the concentrations of the other locations [12]. The concentrations in samples from the control area, about 10 to $20 \mathrm{~km}$ away from the contaminated areas, varied between 811 and $1359 \mathrm{ng} / \mathrm{g}$ with an average value of $990 \mathrm{ng} / \mathrm{g}$. Spatial distribution of CP concentrations in this area was similar to that of the contaminations of PCBs [21]. One sample from a remote area was also analyzed and the concentration was $192 \mathrm{ng} / \mathrm{g}$.

EI-MS $^{2}$ is regarded as being capable of measuring the total CPs in environmental matrices. However, in this study, no response was observed for LCCPs, including the industrial product CP70 and the reference LCCP C22 (72.1\%). Therefore, analysis of LCCPs by GC-EI-MS ${ }^{2}$ needs to be further studied.

\section{Conclusions}

Three instrumental methods for analyzing CPs were compared i006E this paper; GC-ECD, GC-ECNI-LRMS and GCEI-MS ${ }^{2}$. Because ECD and ECNI-LRMS cannot completely eliminate interference, GC-EI-MS ${ }^{2}$ was finally employed 

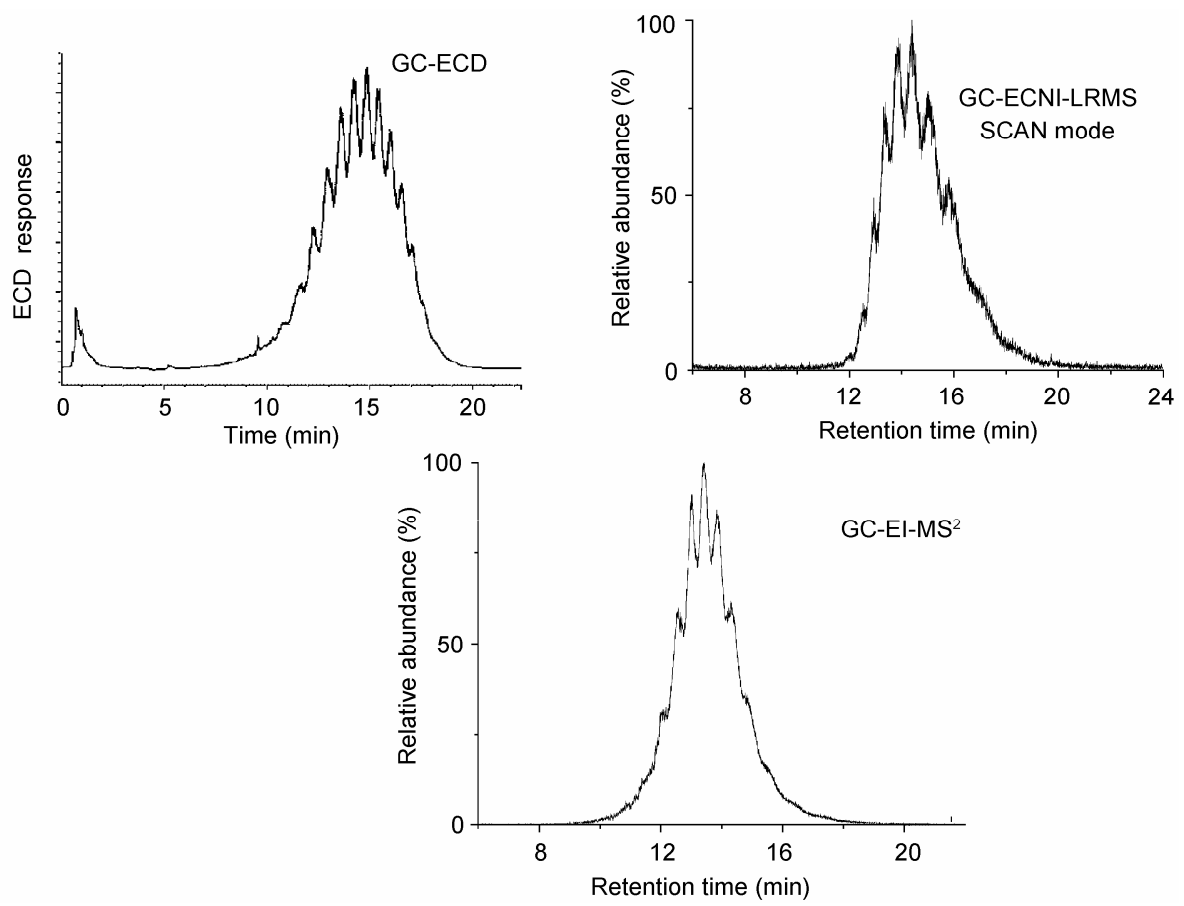

Figure 2 GC-ECD, GC-ECNI-LRMS and GC-EI-MS ${ }^{2}$ chromatograms of industrial product CP52.
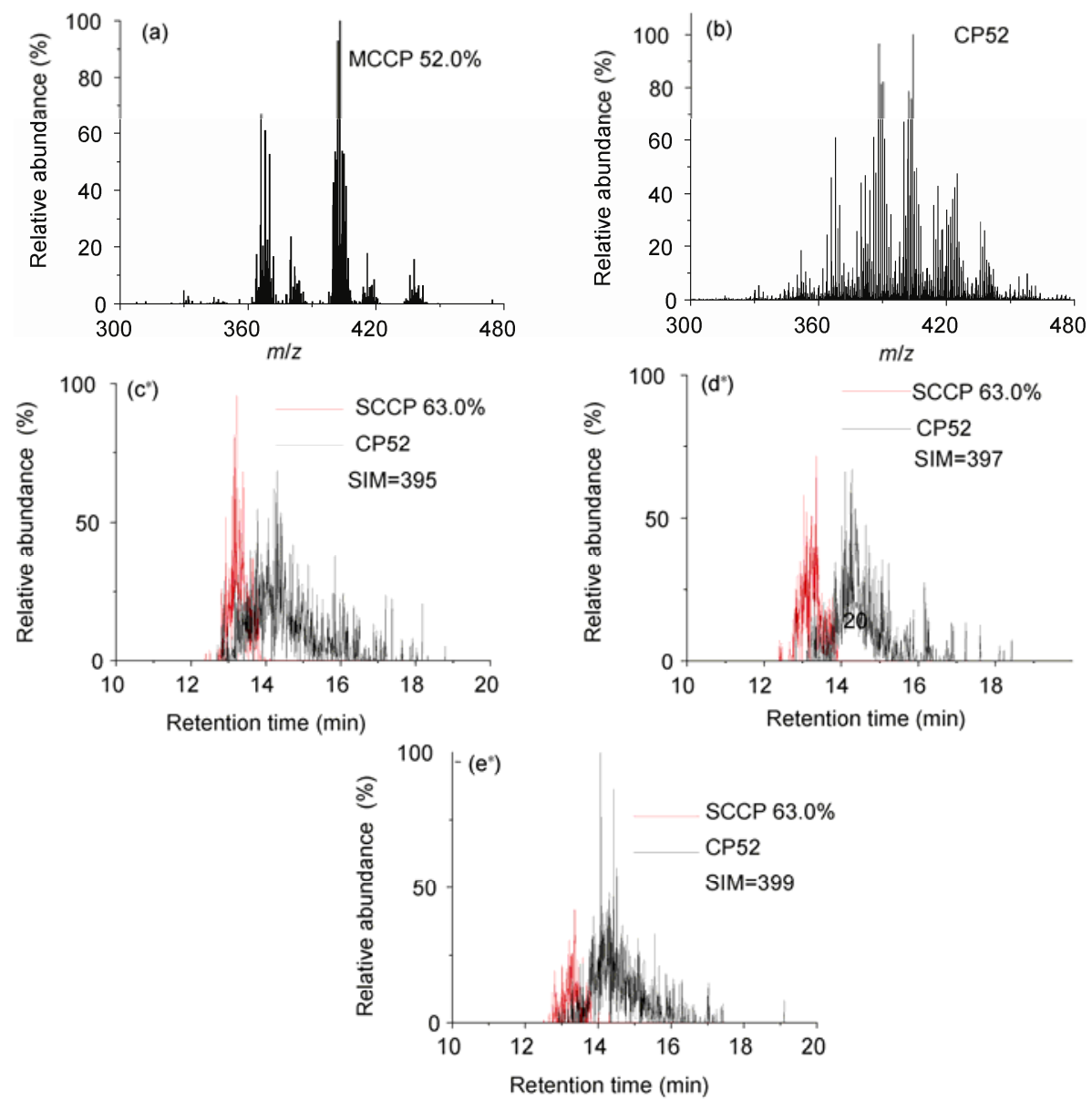

Figure 3 Mass spectrometry and chromatograms of typical ions of CPs standard and industrial products. (a) Mass spectra of MCCP $52.0 \%$ within 13.50-14.50 min; (b) mass spectra of CP52 within 13.50-14.50 min; (c) chromatograms $(\mathrm{m} / \mathrm{z}=395)$ of SCCP $63.0 \%$ and CP52; (d) chromatograms $(\mathrm{m} / z=$ 397) of SCCP $63.0 \%$ and CP52; (e) chromatograms $(\mathrm{m} / \mathrm{z}=399)$ of SCCP $63.0 \%$ and CP52. *The maximum response of (c), (d) and (e) totals to $100 \%$. 


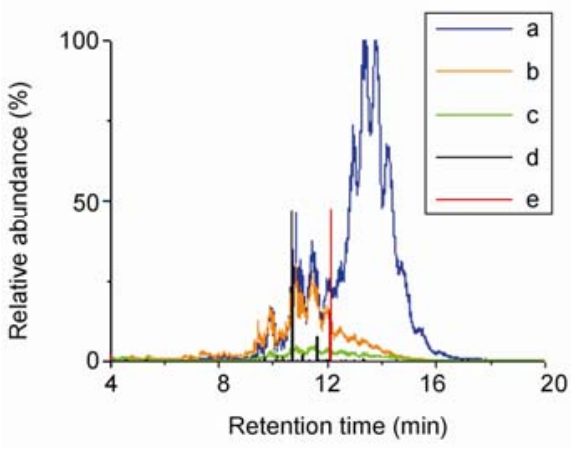

Figure 4 GC-EI-MS ${ }^{2}$ chromatograms of soil samples from different locations. (a) Sample from an e-waste dismantling area; (b) sample from the control area; (c) sample from the background area; (d) recovery standard $\varepsilon-\mathrm{HCH}$; (e) isotopic internal standard ${ }^{13} \mathrm{C}_{10}$-trans-chlordane.

for the detection of CPs in soil samples. A quantitative method for analyzing CPs in soil samples was developed and employed for the preliminary study of the contamination of CPs in an e-waste dismantling area and its outskirt areas. The method showed good reproducibility and recovery, which indicated that it might be utilized to evaluate environmental samples.

This work was supported by the National Basic Research Program of China (2009CB421605) and the National Natural Science Foundation (20897010, 20737003), and the Knowledge Innovation Program of the Chinese Academy of Sciences (RCEES-QN-200703) and the Special Funds for Young Scholars of RCEES, CAS.

1 Castells P, Parera J, Santos F J, et al. Occurrence of polychlorinated naphthalenes, polychlorinated biphenyls and short-chain chlorinated paraffins in marine sediments from Barcelona (Spain). Chemosphere, 2008, 70: 1552-1562

2 Tang E T, Yao L Q. Industry status of chlorinated paraffin and its development trends (in Chinese). China Chlor-Alkali, 2005, 2: 1-3

3 Tomy G T, Stern G A, Muir D C G, et al. Quantifying C10-C13 polychloroalkanes in environmental samples by high-resolution gas chromatography/electron capture negative ion high-resolution mass spectrometry. Anal Chem, 1997, 69: 2762-2771

4 Tomy G T, Stern G A. Analysis of C14-C17 polychloro-n-alkanes in environmental matrixes by accelerated solvent extraction-high-resolution gas chromatography/electron capture negative ion high-resolution mass spectrometry. Anal Chem, 1999, 71: 4860-4865

5 Reth M, Oehme M. Limitations of low resolution mass spectrometry in the electron capture negative ionization mode for the analysis of short- and medium-chain chlorinated paraffins. Anal Bioanal Chem, 2004, 378: 1741-1747

6 Zencak Z, Reth M, Oehme M. Dichloromethane-enhanced negative ion chemical ionization for the determination of polychlorinated $n$-alkanes. Anal Chem, 2003, 75: 2487-2492

7 Moore S, Vromet L, Rondeau B. Comparison of metastable atom bombardment and electron capture negative ionization for the analysis of polychloroalkanes. Chemosphere, 2004, 54: 453-459

8 Zencak Z, Reth M, Oehme M. Determination of total polychlorinated $n$-alkane concentration in biota by electron ionization-MS/MS. Anal Chem, 2004, 76, 1957-1962

9 Randegger-Vollrath A. Determination of chlorinated paraffins in cutting fluids and lubricants. Fresenius J Anal Chem, 1998, 360: 62-68

10 Muir D C, Stern G A, Tomy G T. Chapter 8: Chlorinated paraffins. The handbook of environmental chemistry. In: Paasivirta J, ed. New Types of Persistent Halogenated Compounds. Berlin: Springer-Verlag, 2000. 3

11 Barber J L, Sweetman A J, Thomas G O, et al. Spatial and temporal variability in air concentrations of short-chain $(\mathrm{C} 10-\mathrm{C} 13)$ and medium-chain (C14-C17) chlorinated $n$-alkanes measured in the U.K. atmosphere. Environ Sci Technol, 2005, 39: 4407-4415

12 Nicholls C R, Allchin C R, Law R J. Levels of short and medium chain length polychlorinated $n$-alkanes in environmental samples from selected industrial areas in England and Wales. Environ Pollut, 2001, 114: 415-430

13 Tomy G T, Muir D C, Stern G A, et al. Levels of C10-C13 polychloro- $n$-alkanes in marine mammals from the Arctic and the St. Lawrence River estuary. Environ Sci Technol, 2000, 34: 1615-1619

14 Houde M, Muir D C G, Tomy G T, et al. Bioaccumulation and trophic magnification of short- and medium-chain chlorinated paraffins in food webs from Lake Ontario and Lake Michigan. Environ Sci Technol, 2008, 42: 3893-3899

15 Jansson B, Andersson R, Asplund L, et al. Chlorinated and brominated persistent organic compounds in biological samples from the environment. Environ Toxicol Chem, 1993, 12: 1163-1174

16 Thomas G O, Farrar D, Braekevelt E, et al. Short and medium chain length chlorinated paraffins in UK human milk-fat. Environ Int, 2006, 141: $30-41$

17 Wang Y W, Fu J J, Jiang G B. The Research of environmental pollutions and toxic effect of short chain chlorinated paraffins (in Chinese). Environ Chem, 2009, 28: 1-9

18 Yuan B, Wang Y W, Fu J J, et al. Evaluation of the pollution levels of short chain chlorinated paraffins in soil collected from an E-waste dismantling area in China. Organohalogen Compd, 2009, 71: 3106-3108

19 Korytar P, Parera J, Leonards P E G, et al. Characterization of polychlorinated $n$-alkanes using comprehensive two-dimensional gas chromatography-electron-capture negative ionization time-of-flight mass spectrometry. J Chromatogr A, 2005, 1086: 71-82

20 Randegger-Vollrath A. Determination of chlorinated paraffins in cutting fluids and lubricants. Fresenius J Anal Chem, 1998, 360: 62-68

21 Fu J J, Wang Y W, Zhang Q H, et al. Using apple snail (Ampullarii$d a e)$ as a bioindicator for polychlorinated dibenzo-p-dioxins and dibenzofurans polychlorinated biphenyl, and polybrominated diphenyl ethers in an E-waste dismantling area in southeast China. Organohalogen Compd, 2009, 71: 1143-1145 